\title{
Prácticas audiovisuales críticas: conflicto, arte y política en Chantal Mouffe
}

\section{Critical audiovisual practices: conflict, art and politics in Chantal Mouffe}

TIPO DE TRABAJO: Comunicación.

\author{
PALABRAS CLAVE
}

Videoarte, arte crítico, política, audiovisual, documental.

KEY WORDS

Video art, critical art, politics, audiovisual, documentary film.

RESUMEN

Esta ponencia retoma el texto de Chantal Mouffe Prácticas artísticas y democracia agonística (2007) y analiza su pertinencia en relación a las prácticas artísticas audiovisuales.

El núcleo central de la teoría de Mouffe es su concepción de lo político como la dimensión antagonista inherente a las sociedades humanas. En base a una crítica del esencialismo y racionalismo del pensamiento liberal, Mouffe señala que la identidad no es una esencia, sino un proceso de construcción de subjetividades que se funda en la diferencia con el otro como su "exterior constitutivo". Si la política tiene como punto de partida la constitución de identidades colectivas, estas tienen necesariamente una base antagonista, donde para que haya un "nosotros", tiene que haber un "ellos". El objetivo de la democracia es que ese nosotros/ellos no se articule bajo la lógica del amigo/enemigo, sino en base a la idea de adversarios que aceptan las reglas del juego democrático.

Las teorías de Mouffe nos resultan muy útiles a la hora de entender la relación entre arte y política pues, para la autora, las prácticas artísticas y culturales son fundamentales ya que participan en la construcción de identidades, contribuyen en la reproducción del sentido común aceptado como válido o, por el contrario, trabajan en su impugnación. Por ello, las prácticas artísticas tienen siempre una dimensión política; la denominación "arte político", por tanto, no tendría sentido, aunque sí la del "arte crítico" refiriéndose a formas artísticas que trabajan socavando el orden simbólico dado.

Así, el arte crítico, cuando saca a la luz los conflictos que la supuesta 'paz' neoliberal quiere neutralizar, cuando cuestiona el consenso dominante y fomenta el disenso, está re-politizando lo social y contribuyendo al proyecto democrático. Estudiamos cómo dos obras audiovisuales, una de Patricio Guzmán y otra de Marcelo Expósito, en su empeño por revelar lo reprimido y volver visible aquello que ha sido tapado, no solamente están desarrollando un videoarte crítico, sino que están apostando por una democracia efectiva y plural.

\section{ABSTRACT}

This paper takes up the text of Chantal Mouffe Artistic practices and agonistic democracy (2007) and analyzes its relevance in relation to audiovisual artistic practices (we take into account the extension of the audiovisual field, and we focus on this area less analyzed in that line).

The core of Mouffe's theory is his conception of the political as the antagonistic dimension inherent in human societies. Based on a critique of the essentialism and rationalism of liberal thought, Mouffe points out that identity is not an essence, but a process of construction of subjectivities that is based on the difference with the other as its "constitutive exterior". 
If the political begins with the constitution of collective identities, these necessarily have an antagonistic base, where for there to be a "we", there must be a "them". The goal of democracy is that the relationship between us and them is not articulated under the logic of friends or enemies, but based on the idea of adversaries who accept the rules of the democratic game.

Mouffe's theories are very useful to understand the relationship between art and politics because, for the author, artistic and cultural practices are fundamental because they participate in the construction of identities, contribute to the reproduction of common sense or, on the contrary, they work in their challenge. For this reason, artistic practices always have a political dimension; the denomination "political art", therefore, would not make sense; it does make sense to use the term "critical art" to describe the artistic forms that work undermining the given symbolic order.

In this way, critical art, when it brings to light the conflicts that the supposed neoliberal 'peace' wants to neutralize, when it questions the dominant consensus and fosters dissent, is re-politicizing the social and contributing to the democratic project. In this text we study how two auviovisual works by Patricio Guzmán and Marcelo Expósito, in their effort to reveal the repressed and make visible what has been covered, are not only developing a critical video art, but are also betting on an effective and plural democracy.

\section{INTRODUCCIÓN Y METODOLOGÍA}

Este texto parte de la relectura de Prácticas artísticas y democracia agonística (Mouffe, 2007) para analizar la pertinencia de sus afirmaciones en relación a las prácticas artísticas audiovisuales. Siendo el campo del audiovisual increíblemente amplio, pues incluye las creaciones cinematográficas, las publicitarias de todo tipo, los vídeos que circulan por internet, etc., resulta imposible abarcarlo todo en un solo texto. De ahí que decidamos centrarnos en lo que hemos denominado "prácticas artísticas audiovisuales", que incluyen -entre otros- el vídeo de creación o videoarte y nuevas formas del cine documental.

El núcleo central de la teoría de Mouffe es su concepción de lo político como la dimensión antagonista inherente a las sociedades humanas. En base a una crítica del esencialismo y racionalismo del pensamiento liberal, Mouffe señala, siguiendo los presupuestos del psicoanálisis, que la identidad no es una esencia, sino un proceso de construcción de subjetividades que se funda en la diferencia con el otro. Si la política tiene como punto de partida la constitución de identidades colectivas que deben de organizarse y establecer un orden social, estas tienen necesariamente una base antagonista, donde para que haya un "nosotros", tiene que haber un "ellos". El objetivo de la democracia (agonística, en palabras de la autora) es que ese nosotros/ellos no se articule bajo la lógica del amigo/enemigo, sino con la idea de adversarios que aceptan las reglas del juego democrático, aunque no compartan su interpretación.

La razón por la cual retomar las teorías de Mouffe es porque nos resultan muy útiles a la hora de entender la relación entre arte y política. Para la autora, las prácticas artísticas y culturales son fundamentales en la dimensión de lo político, pues participan en la construcción de identidades, contribuyen en la reproducción del sentido común aceptado como válido o, por el contrario, trabajan en su deconstrucción e impugnación. Por tanto, las prácticas artísticas siempre participan de alguna forma en política, al igual que la política tiene una dimensión estética (Rancière, 2005). Como veremos, bajo esta perspectiva la denominación "arte político" no tiene sentido, aunque sí la de "arte crítico", pues hay formas artísticas que trabajan socavando el orden simbólico dado.

Partiendo de esta premisa, veremos con Mouffe que el arte crítico, cuando saca a la luz los conflictos que la supuesta 'paz' neoliberal quiere neutralizar en pos de intereses económicos, cuando revela lo reprimido por el consenso dominante, está re-politizando lo social y contribuyendo así al proyecto democrático. Pondremos en paralelo dos obras audiovisuales, una de Patricio Guzmán, vinculado al ámbito del cine documental, y otra de Marcelo Expósito, perteneciente al campo de la creación audiovisual en nuestro país. Elegimos estas obras porque, en su empeño por volver visible aquello que ha sido tapado y dar voz a quien no la tiene, no solamente están desarrollando un audiovisual crítico, sino que están apostando por una democracia efectiva. Somos conscientes de que podríamos elegir otras creaciones audiovisuales que trabajan en esta línea; la razón por decantarnos por ellas es, por un lado, porque nos resultaba interesante elegir dos campos de la creación paradigmáticos, el documental y el videoarte, para ver sus cruces, pues veremos cómo la obra de Guzmán se sale de los imperativos estrictos de su género y la obra de Expósito tiene también un carácter documental. Por otro lado, veremos que ambas obras mantienen un nexo temático común que tiene que ver con desenterrar aquello que está oculto a causa de regímenes autoritarios y represivos anteriores (la dictadura de Pinochet en Chile y la dictadura de Franco en España).

\section{Lo político, la política y las prácticas artísticas}

"La historia del sujeto es la historia de sus identificaciones y no hay ninguna identidad oculta que rescatar más allá de estas últimas." (Mouffe, 2007, p. 13). 
Si Mouffe parte de esta afirmación en su estudio sobre las prácticas artísticas en relación a lo político, es para dejar bien claro el papel central de dichas prácticas artísticas y culturales en los procesos de identificación, tanto individuales como colectivos. Y ello desde una posición antiencialista que se apoya en el psicoanálisis de Freud y Lacan para afirmar que la no trasparencia del ego y la estructuración de la personalidad en varios niveles fuera de la conciencia y de la racionalidad del sujeto, ponen en entre dicho, no solamente la unicidad de este último, que deja de ser una esencia cerrada sobre sí misma, sino también la unicidad de las identidades colectivas. Apoyándose en Derrida, Mouffe insiste en que toda identidad se define a partir de su "exterior constitutivo" (2007, p. 15), es decir que se basa en la diferencia con la alteridad. Esta idea tiene importantes consecuencias en política, pues rechaza el objetivismo y el esencialismo dominantes en el pensamiento liberal. Laclau y Mouffe (1987) proponen el término "hegemonía" para reivindicar que todo poder es contingente, podría ser configurado de otra manera y, además, no es externo a las identidades, sino que las constituye mediante prácticas hegemónicas eventuales y reversibles. “(...) La práctica política en una sociedad democrática no consiste en defender los derechos de las identidades preconstituidas, sino más bien es constituir dichas identidades en un terreno precario y siempre vulnerable" (Mouffe, 2007, p. 16). Veremos que señalar la precariedad y vulnerabilidad de los terrenos de juego sociales y mostrar su contingencia es uno de los objetivos del arte crítico.

Resulta también central la distinción que Mouffe hace entre "lo político", definido como el antagonismo inherente a toda sociedad humana (Mouffe, 2007, p. 18) -pues, como hemos dicho, las identidades se forman en contraste con los otros-, y "la política", que puede ser entendida como "el conjunto de prácticas, discursos e instituciones que intentan establecer un cierto orden y organizar la coexistencia humana en condiciones que siempre son potencialmente conflictivas, ya que se ven afectadas por la dimensión de "lo político"." (Mouffe, 2007, p. 18). El objetivo de la política en democracia será, por tanto, que el antagonismo no se trasforme en una relación de amigo/enemigo, sino en una lucha agonista entre adversarios que comparten el mismo terreno de juego democrático de respeto basado en los principios de igualdad y libertad para todos. La disputa central que se juega en democracia es cómo se definen y aplican dichos principios que, como todo en política, no son una esencia, sino que pueden ser objeto de disputas ideológicas pues pueden suscitar interpretaciones diferentes (Mouffe, 2007).

Junto al concepto de hegemonía, y la distinción entre lo político y la política, Mouffe reivindica también el de las pasiones para retratar el marco de lo político. Contrariamente al pensamiento liberal ${ }^{1}$, que concibe la política como un cálculo de intereses objetivables que excluye las pasiones y antagonismos (Mouffe, 2007, p. 17), "la principal tarea de la política democrática no es eliminar las pasiones ni relegarlas a la esfera privada para hacer posible el consenso racional, sino movilizar dichas pasiones de modo que promuevan formas democráticas." (Mouffe, 2007, p. 20). Bajo este prisma, si el pensamiento economicista y consensualista liberal despolitiza la vida social, las prácticas artísticas como "movilización de las pasiones y las formas colectivas de identificación" (p. 58), en su trabajo directo con las subjetividades, las emociones, los sentimientos en conflicto, pueden ser un factor más en esa búsqueda de re-politizar lo social que el proyecto de una democracia "plural y radical" (Mouffe, 2007, p. 18) necesita².

\section{Arte político / arte crítico}

¿Se puede hablar entonces de arte político? Entrevistada por Rosalyn Deutsche, Branden W. Joseph y Thomas Keenan (Mouffe 2007, p. 25), Mouffe afirma que las prácticas artísticas, siendo uno de los niveles en los que se constituyen las identificaciones e identidades por medio del trabajo con las pasiones (p. 26), son fundamentales en el ámbito de lo político. $Y$, en la línea del pensamiento de Rancière, va más allá cuando señala que siempre "en lo político hay una dimensión estética y en el arte una dimensión política" ( $p$. 67).

Para entender esta afirmación, conviene retomar al citado autor (Rancière, 2007) cuando define la política diferenciándola de lo que él llama la "policía". Esta última sería un orden social que implica un régimen de sensibilidad aceptado (de acuerdo a reglas impuestas socialmente) que jerarquiza sujetos y objetos permitiendo que unos sean visibles y otros invisibles, que unos tengan voz y otros no. La política, en cambio, surge para Rancière como ruptura del orden dominante, implicando una reordenación de los lugares que ocupaba cada uno, cambiando el régimen de lo visible y lo decible, es decir, de lo que está permitido en términos de habla, visibilidad, etc.

Al igual que para Mouffe, la esencia de la política es el conflicto, aunque lo que Mouffe llama "hegemonía" y "contra-hegemonía", Rancière lo denomine policía y política (definida, insistimos, como oposición al orden policial).

\footnotetext{
${ }^{1}$ En su texto Mouffe distingue dos formas de liberalismo: la economicista, según la cual los individuos racionales buscan legítimamente su interés personal (perspectiva profundamente individualista e instrumental, pues la política es concebida como un mercado de intereses donde hay que ver cómo se asignan los recursos); y la consensualista, que incluye una dimensión ética pero basada en la creencia de que es posible alcanzar un consenso universal y racional a través del libre debate (Mouffe, 2007).

${ }^{2}$ En su entrevista con Rosalyn Deutsche, Branden W. Joseph y Thomas Keenan celebrada en el año 2000, Chantal Mouffe afirma: "Lo que hace actuar políticamente a las personas es lo que he llamado "pasiones". Las identificaciones colectivas tienen que ver con el deseo, con fantasías, con todo lo que precisamente no son intereses o lo racional. (...) la política debe hablar a las personas sobre sus pasiones para movilizarlas hacia proyectos democráticos" (Mouffe, 2007, p. 57).
} 
Un concepto clave aquí es el de división o redistribución de lo sensible, que sería la repartición de espacios y tiempos, de lo visible, del lenguaje:

La política consiste en reconfigurar la división de lo sensible, en introducir sujetos y objetos nuevos, en hacer visible aquello que no lo era, en escuchar como a seres dotados de la palabra a aquellos que no eran considerados más que como animales ruidosos. Este proceso de creación de disensos constituye una estética de la política, (...) (Rancière, 2005, p. 15).

En la misma línea, Mouffe refiere la política a la ordenación simbólica de las relaciones sociales que ponen en escena la coexistencia humana, lo cual implica una dimensión estética de la misma. (Mouffe, 2007, p. 67).

En cuanto a la dimensión política del arte, para Mouffe: “(...) las prácticas artísticas desempeñan un papel en la constitución y el mantenimiento de un orden simbólico dado o en su impugnación (...)” (p. 67), por lo cual siempre tienen una dimensión política. De la misma forma, Rancière afirma que "(...) lo propio del arte consiste en practicar una distribución nueva del espacio material y simbólico. Y por ahí es por donde el arte tiene que ver con la política." (Rancière, 2005, p. 13).

De ahí se deduce -por responder a la pregunta que formulábamos antes- que arte y política no son formas separadas, son "dos formas de división de lo sensible dependientes, tanto una como otra, de un régimen específico de identificación." ${ }^{3}$ (Rancière, 2005, p. 16). De hecho, en la entrevista ya citada, Rosalyn Deutsche señala que el término arte político provoca el equívoco de que pueda haber un arte que no lo sea, lo cual no resulta posible pues, como hemos señalado ya, todas las formas de la práctica artística se mueven entre dos polos: la reproducción del sentido común dado, es decir, del régimen de visibilidad hegemónico, o bien su deconstrucción e impugnación (Mouffe, 2007).

Otra cuestión es que pueda haber un tipo de arte que admita claramente su dimensión política apostando por "pensar políticamente" (Mouffe, 2007, p. 60-61), es decir, partiendo del reconocimiento del conflicto como base de las sociedades humanas, algo de lo cual el liberalismo es incapaz. El arte crítico es claramente contra-hegemónico ${ }^{4}$, pues rechaza la idea de "orden natural" o "sentido común" que el sistema hegemónico quiere generalizar y señala el carácter construido, es decir, contingente, de cualquier orden dado; se coloca así del lado de la impugnación fomentando el disenso como primer paso para ver y pensar de otra forma.

Para Mouffe, el arte crítico tiene dos objetivos claros: por un lado, "revelar todo lo reprimido por el consenso dominante" (2007, p. 67) volviendo visible lo que suele ser borrado y, por el otro, "dar voz a todos los silenciados en el marco de la hegemonía existente." (p. 67). Una vez más, la cuestión de la visibilidad y de la toma de la palabra es central; si Rancière (2004) define la estética de la política como esa redistribución de lo sensible que saca a la luz a lo que estaba oculto y dota de palabra a quien no la tenía, podemos pensar que el arte crítico es aquel que hace suya esa dimensión estética de la política de forma programática.

\section{Ejemplos de arte crítico audiovisual}

Como decíamos en la introducción, nos interesa la relectura del texto de Mouffe para indagar su pertinencia en relación a la creación audiovisual. Más allá del cine más convencional sumido en las exigencias de taquilla, de la publicidad audiovisual al servicio de los intereses de las empresas y más allá de formas del documental absorbidas por el discurso dominante -todas ellas formas que reproducen, como hemos dicho, los regímenes de visibilidad y discursos hegemónicos-, existen otras vías para la creación con imágenes en movimiento y sonidos que se mantienen en los márgenes de este panorama. El videoarte, las nuevas formas del documental, la video-guerrilla o el vídeo comunitario, buscan otras formas de trabajar con la imagen móvil, indagando maneras distintas de mirar y de hacer ver fuera de las industrias culturales.

En su texto, Chantal Mouffe cita a Richard Noble ${ }^{5}$ que categoriza cuatro estrategias o líneas de trabajo básicas del arte crítico: aquellas obras que abordan directamente, de manera crítica, una realidad política; aquellas que dan voz a sectores considerados marginales; aquellas que problematizan sobre sus propias condiciones de producción y distribución; y, finalmente, las obras que intentan retratar escenarios utópicos construidos “en torno a valores en oposición al ethos del capitalismo tardío” (Mouffe, 2007, p. 69).

\footnotetext{
${ }^{3}$ Para Rancière todo arte se vincula a una forma específica de visibilidad y de discursividad que la identifica como arte y la vincula a una cierta forma de política (Rancière, 2004, p. 63). “No hay arte, evidentemente, sin un régimen de percepción y de pensamiento que permita distinguir sus formas como formas comunes. Un régimen de identificación del arte es aquel que pone determinadas prácticas en relación con formas de visibilidad y modos de inteligibilidad específicos." (Rancière, 2005, p. 18). En relación a esos regímenes de identificación, el autor distingue 3 tipos: el régimen ético, el representativo y el estético. Ver Rancière 2005, pp. 18-20.

${ }^{4}$ Así define la autora lo contra-hegemónico: "Todo orden hegemónico es susceptible de impugnación por prácticas hegemónicas contrarias, es decir, prácticas que intentarán desarticular el orden existente con vistas a instalar otra forma de hegemonía." (Mouffe, 2007, p. 63).

${ }^{5}$ Richard Noble: "Some Provisional Remarks on Art and Politics", en The Showroom Annual, 2003/2004.
} 
Para no extendernos demasiado, no vamos a comentar ejemplos de cada línea de trabajo, pero sí que queremos empezar recordando la importancia de la video-guerrilla de los años 60/70 del siglo XX, que se podría incluir en la primera tendencia citada por Mouffe, pues utilizaba el vídeo como herramienta de denuncia social. En aquellos años de inicio del dispositivo videográfico, su versatilidad, facilidad de manejo y bajo coste hicieron que fuera visto como una posible herramienta de intervención social y de experimentación artística, lo cual provocó una patente ligazón del videoarte a los movimientos políticos de la época. Colectivos como Raindance, Global Village, Videofreex, Vidèo Out o Video Nou, utilizaron la imagen en movimiento como vehículo de la cultura underground y medio de contra-información, realizando, entre otras producciones, grabaciones de manifestaciones, asambleas o movimientos sociales ${ }^{6}$. Esta tendencia de los inicios del vídeo, tuvo su reactivación a partir de la primera década de este siglo en lo que he denominado "vídeo comunitario" (Rodríguez Mattalía, 2016), donde, en un contexto de crisis económica y de descrédito de la clase política tradicional, vuelve a utilizarse el vídeo como vía de cambio social ${ }^{7}$, esta vez aprovechado Internet como canal de difusión global.

En la introducción anunciábamos que, por razones de espacio -pues la extensión de esta ponencia no permite, evidentemente, abarcarlo todo-, queremos poner en paralelo dos obras audiovisuales -una de Patricio Guzmán y otra de Marcelo Expósito- que pertenecen a dos campos de la creación paradigmáticos, el documental y el videoarte, para ver sus cruces, ya que en ambas tendencias se puede dar una libertad creativa que responde a una relativa independencia respecto a las industrias culturales y sus imperativos económicos. Veremos, además, que ambas obras tienen un nexo temático común.

En la actualidad también son notables toda una serie de documentales que, rechazando las reglas encorsetadas del género en su versión más institucional ${ }^{8}$-donde el enunciador se coloca en el lugar del saber que ofrece una mirada pretendidamente "objetiva" de lo real-, ofrecen miradas distintas sobre aquello que nos rodea, mostrando aquello que está oculto en el discurso dominante y dando voz a quien no la tiene (dos empeños del arte crítico definido por Mouffe).

En esta línea, queremos destacar el trabajo de Patricio Guzmán ${ }^{9}$ con Nostalgia de la luz (2010) que se centra en el desierto de Atacama (Chile) para desantañar lo que el desierto esconde. El documental lleva en paralelo dos líneas argumentales: el trabajo del observatorio astronómico mundial, donde los astrónomos aprovechan la sequedad extrema de dicho desierto para mirar el universo y, por otro lado, la búsqueda de cadáveres de desaparecidos, asesinados por la dictadura de Pinochet, que enterró a muchos de ellos en el desierto sin pensar que la sequedad del suelo preservaría sus huesos intactos para siempre. Mujeres que indagan la tierra buscando a sus seres queridos sin rendirse ante el empeño de las autoridades de mirar para otro lado: "Ojalá los telescopios no miraran solo al cielo", dice una de las protagonistas que no se conforma con la versión oficial y sigue buscando en el desierto.

Pero además de esta tendencia documentalista, hay también toda una serie de artistas del vídeo que lo han utilizado para realizar ensayos audiovisuales que exponen problemáticas sociales, sacan a la luz conflictos o muestran la fragilidad de los lugares comunes que pueblan nuestra cultura. Es el caso del vídeo El año en el que el futuro acabó (comenzó) (2007) de Marcelo Expósito ${ }^{10}$, que nos interesa especialmente pues pone en tela de juicio la transición democrática española. Se inicia con una fotografía ${ }^{11}$ donde dos jóvenes preparan urnas para las elecciones de 1977. Toda la primera parte del vídeo está realizada con imágenes de archivo, tanto fotográficas como films, que recorren hacia atrás el tiempo transcurrido desde ese año de las primeras elecciones democráticas tras la dictadura de Franco, hasta llegar al inicio de la Guerra Civil. El montaje es muy rápido, casi trepidante, y las imágenes están enmarcadas por un iris circular que focaliza aún más la atención del espectador. Este, tras unos segundos de visionado, comprende a dónde se dirige dicho montaje que partía de la esperanzadora foto de los jóvenes con la urna: 1936, la imagen de Franco y sus tropas, las banderas nazis, los primeros bombardeos. El movimiento hacia atrás en el tiempo deja clara la apuesta del artista: revisar, no quedarnos con la simple versión de que nuestro futuro empezó en 1977 (de ahí el guiño del título).

La última imagen del montaje es el rostro en blanco y negro de un niño pequeño, que mira a la cámara con unos ojos ya atravesados por el miedo a la guerra. En ese momento, la música, que había acompañado a las imágenes en su frenesí, se detiene para dar paso al ruido ambiente de una excavación: planos del suelo terroso, de manos jóvenes excavando minuciosamente, plano cerrado de unas

\footnotetext{
${ }^{6}$ Sobre este tema se puede consultar Palacio (2014).

${ }^{7}$ Por ejemplo, numerosos movimientos antiglobalización, los Indignados del 15M, Occupy Wall Street, etc., han tenido una producción audiovisual que ha dado visibilidad a sus acciones y demandas sociales.

${ }^{8}$ Recogen la tendencia de finales de los años 50 y los 60 de búsqueda de un cine libre de propaganda institucional (tanto del gobierno como de intereses privados), que apostaba por vías de financiación alternativas: el Cinéma Verité en Francia, el Direct Cinema en Estados Unidos o el Free Cinema en Inglaterra, por ejemplo.

${ }^{9}$ Ya en los años 70, este documentalista apostó por una mirada a pie de calle que retratara la lucha del pueblo desde la base: La batalla de Chile (1975) relata los eventos ocurridos en su país entre 1972 y septiembre de 1973 con el asesinado de Allende y el golpe de estado de Pinochet.

${ }^{10}$ Obra producida por el CCCB, Centro de Cultura Contemporánea de Barcelona y seleccionado para el Festival NRVP, Nuevas Realidades Video Políticas, celebrado en la Universidad Politécnica de Valencia en 2012: https://nrvp.wordpress.com/

${ }^{11}$ De Gustavo Catalán.
} 
manos sosteniendo un cráneo. Entendemos entonces que se trata de la excavación ${ }^{12}$ de una fosa común y que el montaje anterior, en su salto hacia atrás en el tiempo, nos ha llevado a un presente que se esfuerza por desentrañar de la tierra pedregosa los cadáveres que continúan escondidos, en la misma línea que las mujeres del desierto de Atacama en Chile. Llama la atención que los arqueólogos que están trabajando (para la Asociación para la Recuperación de la Memoria Histórica de Cuenca) son tan jóvenes como aquellos dos muchachos que sostenían la urna de 1977, pero lo hacen en 2007, justo 30 años después.

Como este vídeo muestra, no fue suficiente la reanudación de la democracia por medio del voto para hacer justicia a nuestros muertos que, de hecho, siguen enterrados a cientos en las cunetas de este país. Expósito despliega así una lectura crítica sobre la transición democrática reivindicando que no se hizo sin costes: el olvido de muchas víctimas, la falta de justicia ante muchos crímenes y el silencio de las autoridades, todo ello, es pos de una democracia que se vendió como posible únicamente si se mantenía dicho silencio $^{13}$.

\section{CONCLUSIONES}

"La especificidad de la democracia moderna reside en el reconocimiento y la legitimación del conflicto y en el rechazo a reprimirlo imponiendo un orden autoritario." (Mouffe, 2007, p. 20). Las dos obras que hemos comentado denuncian la pervivencia del silencio en la democracia actual (de Chile, de España) sobre los crímenes cometidos por las dictaduras anteriores. Así como el orden autoritario reprime el conflicto (la "policía" de Rancière), no podemos aceptar que nuestras democracias se asienten en el silencio aduciendo que la "reconciliación nacional" así lo requiere.

Estamos con Mouffe cuando afirma que, para que las prácticas artísticas jueguen un papel en política, primero es necesario "(...) el reconocimiento de lo político en su dimensión antagonista, así como del carácter contingente de cualquier tipo de orden social." $(2007$, p. 60). En esa línea, los citados audiovisuales señalan la contingencia de nuestras formas de democracia y la precariedad de ese equilibrio inestable al que hemos llegado y, lo que es muy importante, lo hacen apelando a nuestras pasiones, a aquello que hemos perdido o escondido para intentar construir democracia olvidando el orden autoritario anterior.

De hecho, la autora advierte del peligro de movilizar las pasiones de forma antidemocrática y excluyente (en la línea del racismo, la xenofobia, el sexismo, etc.) (2007, p. 58), donde el despuntar actual de movimientos de extrema derecha puede ser visto como una consecuencia de la despolitización general de nuestras sociedades que no permite el desarrollo de un pluralismo efectivo ya que "una de sus tareas principales (del pluralismo) es plantearse modos de frenar las tendencias a la exclusión presentes en todas las construcciones de identidad colectiva" (p. 18). En suma, para Mouffe: "Cuando la dinámica agonística del sistema pluralista se ve obstaculizada por la falta de identidades democráticas con las que poder identificarse, existe el riesgo de que se multipliquen las confrontaciones sobre identidades esencialistas y valores morales no negociables." (p. 20).

De esta forma, si las leemos con la lógica de Mouffe, las obras citadas muestran que escarbar la tierra no es un simple empeño revisionista que solo se preocupa por el pasado desestabilizando el presente, sino que es una apuesta por una democracia efectiva $y$ plural que reconozca tanto los conflictos que llevamos arrastrando durante décadas, como aquellos que tenemos en ciernes, y que trabaje, sin miedo, a partir de estos.

\section{FUENTES REFERENCIALES}

Laclau, E. y Mouffe, Ch. (1987). Hegemonía y estrategia socialista: hacia una radicalización de la democracia. Madrid: Siglo XXI.

Mouffe, Ch. (2007). Prácticas artísticas y democracia agonística. Barcelona: Museu d’Art Contemporani de Barcelona y Servei de Publicacions de la Universitat Autònoma de Barcelona.

\footnotetext{
${ }^{12}$ Se trata de una excavación en la Tahona de Uclés (Cuenca) realizada entre 2005 y 2007 por la Asociación para la Recuperación de la Memoria Histórica de Cuenca. Se encontraron 439 cadáveres de soldados republicanos fallecidos durante la Guerra Civil, de represaliados por el franquismo o de fusilados en la posguerra.

${ }^{13}$ Queremos destacar en esta línea temática el documental recientemente estrenado titulado El silencio de otros (2018), dirigido por Almudena Carracedo y Robert Bahar. Se centra en mostrar cómo todavía muchas víctimas o familiares de víctimas del régimen franquista continúan buscando justicia. En una filmación que abarca seis años, la película sigue el proceso de querella que un grupo de víctimas y familiares iniciaron por medio de una jueza argentina, pues en España la ley de amnistía -o "pacto del olvido"- impide que se haga justicia. Los querellantes exigen, entre otras cosas, recuperar los huesos de sus familiares asesinados, que se juzgue a todos los torturadores que aún no han pagado por sus crímenes de lesa humanidad, o que se explique qué sucedió con numerosos bebés desaparecidos.
} 
Rodríguez Mattalía, Lorena

Prácticas audiovisuales críticas: conflicto, arte y política en Chantal Mouffe

IV Congreso INTERNACIONAL DE INVESTIGACIÓN EN ARTES VISUALES ANIAV 2019 IMAGEN [N] VISIBLE]

http://dx.doi.org/10.4995/ANIAV.2019.9022

Mouffe, Ch. (2012). La paradoja democrática. El peligro del consenso en la política contemporánea. Barcelona: Gedisa.

Mouffe, Ch. (2014). Agonística. Pensar el mundo políticamente. Buenos Aires: Fondo de Cultura Económica.

Palacio, M. (2014). El eslabón perdido. Apuntes para una genealogía del cine documental contemporáneo. Revista Cine Documental, 9, 91-117.

Rancière, J. (2004). Malaise dans l’esthétique. París: Galilée.

Rancière, J. (2005). Sobre políticas estéticas. Barcelona: Museo de Arte Contemporáneo y Universidad Autónoma de Barcelona.

Rancière, J. (2007). El desacuerdo: política y filosofía. Buenos Aires: Nueva Visión.

Rodríguez Mattalía, L. (2016). Videoarte comunitario, resistencia y multitud. En W. García Puchades y M. Miquel (eds.), La cultura de lo común. Prácticas colectivas del siglo XXI (p. 93-106). Valencia: Editorial de la Universitat Politècnica de València. 